\title{
APLICAÇÃO DE UM MODELO DE EQUILÍBRIO PARCIAL PARA O TRANSPORTE DE ETANOL
}

\author{
Jamile de Campos Coleti \\ Instituto de Economia - Universidade Estadual de Campinas \\ jamile.coleti@gmail.com \\ Andrea Leda Ramos de Oliveira \\ Faculdade de Engenharia Agrícola - Universidade Estadual de Campinas \\ Andrea.oliveira@feagri.unicamp.br
}

\begin{abstract}
Resumo
A busca por fontes de energia renováveis tem aumentado a demanda mundial de etanol. O Brasil ocupa a posição de segundo maior produtor mundial de etanol, porém os custos para transportar essa produção estão cada vez mais altos. O objetivo do trabalho é analisar as alternativas de transporte do etanol frente às condições logísticas vigentes no Brasil. Para tanto, propõe-se um modelo de equilíbrio parcial na forma de um Problema de Complementaridade Mista (PCM) aplicado ao etanol. Avaliou-se dois cenários, o primeiro se trata de um cenário base com rotas de transporte com o modal rodoviário e intermodal, no segundo estimou-se uma redução de $15 \%$ no valor do frete. O cenário 2 apresentou os melhores volumes de comercialização em relação ao cenário base, indicando que os projetos viários que priorizem a intermodalidade, implicam reduções no custo de transporte e conferem uma melhoria na eficiência do sistema logístico. Destaca-se também, que a hipótese de intermodalidade do cenário 2 refletiu-se em ganhos de competitividade no mercado internacional, isso porque $100 \%$ das rotas com destino ao mercado externo são intermodais.
\end{abstract}

Palavras-Chaves: etanol, logística, equilíbrio espacial

\begin{abstract}
The search for renewable energy sources have been increasing the global demand for ethanol. Brazil holds the position as the second largest ethanol's producer of the world, but the costs to transport this production are increasingly high. The main idea of this paper is to analyze the alternatives ethanol transportation in face of the logistics of the prevailing conditions in Brazil. Therefore, it is proposed a partial equilibrium model as a Mixed Complementarity Problem (PCM) applied to ethanol. It was evaluated two scenarios, the first is a baseline scenario with shipping routes on road modal and intermodal, the second estimated that the $15 \%$ reduction in the value of rail freight. The scenario 2 presented the best marketing volumes with an increase compared to baseline, indicating that the road projects that prioritize intermodality, implying reductions in the cost of transport and bestow an improvement in the efficiency the logistics system. Also noteworthy is that the case of intermodal scenario 2 reflected gains in competitiveness on the international market, because $100 \%$ of the routes to the external market are intermodal.
\end{abstract}

Keywords: $\quad$ ethanol, logistics, spatial equilibrium. 


\section{INTRODUÇÃO}

A expansão do agronegócio tem sido marcante na sociedade brasileira, caracterizando-se por cadeias produtivas cada vez mais integradas e pelo uso intensivo de capital nos diversos segmentos que o compõe. Considerando-se alguns aspectos da agricultura, tais como: a elevada participação no PIB, manutenção do saldo positivo da balança comercial e a contribuição para o controle da inflação, evidencia-se sua importância para o desempenho da economia brasileira [1].

A diversificação produtiva, especialização na produção, aumentos de produtividade, mecanização da colheita e otimização do sistema logístico são colocadas como estratégias que foram adotadas para enfrentar o afastamento do Estado na década de 90 e que são de extrema importância para o desenvolvimento do setor [2].

Apesar das deficiências na infraestrutura de transporte nacional, a comercialização de produtos agrícolas tem se apoiado em sistemas logísticos que permitem tanto a redução de custos de comercialização como a inserção em mercados globalizados [3].

Uma logística eficiente é uma condição básica para a competitividade de todos os setores da economia, já que busca orientar os processos produtivos, atendendo a demanda por produtos no sentido de qualidade, prazos, assistência técnica e inovações [4].

O setor sucroalcooleiro é um dos segmentos que colaboram para posição de destaque do agronegócio brasileiro. Num contexto altamente competitivo causado pela globalização, este segmento produtivo vem superando barreiras, desde a criação do Proálcool e passando pela crise econômica de 2009, aumentando cada vez mais sua produção e inserção no mercado mundial. O setor vem buscando o aumento de competitividade, apoiado na produção e difusão de tecnologia, de forma que a indústria nacional consiga obter altos níveis de produtividade agrícola e industrial. Porém, com o surgimento de novas tecnologias, matériasprimas, novos produtos, além de diferentes modelos de negócio e estratégias empresariais, a hegemonia que se tinha devido ao pioneirismo no setor começou a ser ameaçada [5].

A expansão de área plantada de cana-de-açúcar pode desempenhar forte pressão no sistema de transporte de etanol. O Brasil é o segundo maior produtor e consumidor de etanol do mundo, ficando atrás apenas dos Estados Unidos, porém seu poder de competitividade é reduzido devido aos problemas de infraestrutura e logística que causam incertezas quanto às garantias de fornecimento.

O Brasil vem apresentando grande participação no comércio internacional de etanol, gerando aspectos positivos para a economia, porém tem sofrido com as limitações logísticas, a exemplo da precariedade das rodovias, baixa eficiência e capacidade das ferrovias - já que muitos trechos encontram-se desativados, e pela desorganização e excesso de burocracia nos portos - que geram filas de caminhões que consequentemente atrasam os prazos de entregas, prejudicando a competitividade do Brasil no exterior [6].

Os custos de transporte são influenciados, basicamente pelos seguintes fatores econômicos: a distância, o volume, a densidade, a facilidade de acondicionamento e de manuseio, a responsabilidade e o mercado [7]. Cerca de 46 bilhões de litros de etanol são utilizados no mundo como fonte de combustível e o Brasil produz cerca de 40\%, destes, 10 bilhões são produzidos no estado de São Paulo onde a produção é escoada, majoritariamente, através de transporte rodoviário. Se alternativas de transporte fossem de fato implementadas, além de reduzir os custos, o impacto ambiental de transportes como o hidroviário, ferroviário ou dutoviário seria menor quando comparado ao modal rodoviário.

Dessa maneira, o objetivo da pesquisa é analisar as alternativas de transporte para diferentes rotas de etanol frente às condições da logística vigentes no Brasil, avaliando as implicações das limitações da infraestrutura de transporte na promoção do aumento da competitividade do etanol no mercado nacional e internacional.

Para tanto, propõe-se um modelo de equilíbrio parcial na forma de um Problema de Complementaridade Mista (PCM) aplicado ao etanol. O uso do modelo também visa avaliar 
diferentes cenários relacionados à logística de movimentação do etanol com vistas à orientação de novos projetos viários capazes de aumentar a competitividade do setor.

No item 2 é apresentada uma breve revisão referente ao etanol brasileiro e suas formas de transporte. No item 3, é apresentada a metodologia utilizada. No item 4, os resultados obtidos e no item 5 , uma breve conclusão.

\section{ETANOL E SUAS FORMAS DE TRANSPORTE}

\subsection{O ETANOL BRASILEIRO}

O Brasil ocupa a posição de segundo maior produtor de etanol do mundo [8]. Na safra 2012/2013 o Brasil produziu cerca de 23 milhões de $\mathrm{m}^{3}$, ficando atrás apenas dos Estados Unidos que produz aproximadamente 50 milhões de $\mathrm{m}^{3}$ [9].

A demanda por etanol depende basicamente da frota movida a álcool, que desde 2003 está aumentando devido à substituição da frota movida a gasolina por carros movidos a etanol.

O aumento dos preços do petróleo junto com a forte demanda por fontes de energia limpas e renováveis, aliado à intensa comercialização de carros flexfuel, criou um cenário bastante favorável para produção. $\mathrm{O}$ etanol apresenta também vantagens ambientais, já que sua combustão gera cerca de $70 \%$ de dióxido de carbono a menos que a gasolina.

Para a safra de 2019-2020, as estimativas são de que o país esteja produzindo um total de 62,91 bilhões de litros de etanol, que representaria um acréscimo de 146\% na quantidade produzida em 2009-2010 [10].

Se observar a distribuição das unidades produtoras de açúcar e etanol no Brasil, percebe-se que a produção está concentrada na região Centro-Sul (90\%) e na região Nordeste com menor intensidade (10\%).

O estado de São Paulo é responsável por processar cerca de 55\% do total de matéria prima produzia no país e ocupa posição de principal Estado produtor de etanol com mais de $50 \%$, em seguida temos o Estado de Goiás responsável por 9\%, Minas Gerais (8\%), Paraná (6\%), Mato Grosso do Sul (6\%) e Mato Grosso (2\%).

Em relação às exportações, foi exportado 3,09 milhões de metros cúbicos de etanol em todo o ano de 2012, um volume 55,3\% maior do que 2011, quando foram exportados cerca de 1,96 milhões de metros cúbicos de etanol [11].

$\mathrm{Na}$ situação atual em que o setor se encontra, onde várias unidades produtoras estão sendo fechadas e o número de unidades desativadas vem, desde 2008, ultrapassando a quantidade de novas unidades, há uma urgência em relação à construção de novas vantagens, seja por meio de investimento em conhecimento básico e aplicado ou em tecnologias capazes de impactar a competitividade das formas tradicionais de produção, distribuição e comercialização e em preparar as novas formas [5].

O aumento da demanda pelo etanol tem impulsionado a expansão da fronteira da produção sucroalcooleira e neste processo alguns limitantes para o desenvolvimento da cadeia emergem. Dentre os principais entraves para o setor encontra-se a infraestrutura logística.

\subsection{TRANSPORTE DE ETANOL}

A movimentação de etanol se inicia em uma das unidades produtoras de etanol do país e são transferidos para os centros coletores para serem armazenados, por vezes, o produto pode ser transferido diretamente para a base de distribuição. Esse transporte é feito majoritariamente via modal rodoviário.

Após o recebimento no centro coletor, o etanol é transportado até as bases de distribuição e posteriormente, das bases até o mercado interno ou até os portos. O produto que tem como destino o mercado interno (postos de abastecimento ou revendedor retalhista) é em geral enviado pelo modal rodoviário [12]. 
A Tabela 1 ilustra a exportação de etanol por local de embarque nos portos brasileiros. Pode-se verificar que o Porto de Santos é o principal local de embarque do produto. Tal fato ocorre devido à maior parte da produção brasileira estar localizada na região Centro-Sul do país.

Tabela 1. Exportação anual de etanol por porto de embarque $\left(\mathrm{em} \mathrm{mil} \mathrm{m} \mathrm{m}^{3}\right)$

\begin{tabular}{c|l|c|c}
\hline Portos de Exportação & 2011 & 2012 & 2013 \\
\hline Santos & $1.499,84$ & $2.447,99$ & $2.519,85$ \\
Paranaguá & 272,04 & 431,06 & 287,17 \\
Maceió & 163,92 & 120,42 & 35,78 \\
Suape & 7,96 & 34,20 & 16,08 \\
São Luís & 0,00 & 14,76 & 9,80 \\
Vitória & 0,00 & 5,12 & 9,84 \\
Outros & 23,80 & 44,75 & 24,49 \\
\hline Total & $1.967,56$ & $3.098,30$ & $2.903,01$ \\
\hline
\end{tabular}

Fonte: UNICA (2014) [25].

O Brasil é o segundo maior produtor e consumidor de etanol do mundo, ficando atrás apenas dos Estados Unidos, porém seu poder de competitividade é reduzido devido aos problemas de infraestrutura e logística que causam incertezas quanto às garantias de fornecimento.

Assim como, a decisão de um usuário por um modal para a movimentação de sua carga depende de dois fatores: os custos e as características operacionais do serviço de transporte [13].

Atualmente o transporte é realizado através das seguintes modalidades: rodoviário, ferroviário, aquaviário, dutoviário e aéreo, sendo que a grande maioria das commodities agrícolas são transportadas via modal rodoviário.

As cinco dimensões mais importantes no que refere às características operacionais do serviço de transporte são: velocidade, consistência, capacitação, disponibilidade e frequência [14].

O modal mais veloz é o áereo, por possuir o menor transit-time - que por sua vez é o que apresenta maior custo; o modal com maior consistência é o dutoviário, obtém vantagem por não ser afetado pelas condições climáticas ou de congestionamentos; o modal com maior capacidade é o aquaviário, que praticamente não possui limitações para o tipo de produto e volume a ser transportado; em relação à disponibilidade o modal rodoviário não apresenta qualquer tipo de limitação; por fim, o modal dutoviário é capaz de realizar um maior número de viagens em determinado tempo, por isso apresenta maior frequência [14].

É evidente a necessidade da viabilização e integração dos corredores de transporte intermodais (rodovia, ferrovia, dutovia e hidrovia) como instrumento para alavancar a competitividade no transporte de cargas, unindo as áreas de produção, os centros consumidores e o mercado internacional [15].

\section{METODOLOGIA}

Diferentes abordagens teóricas têm sido usadas para mensurar as interações entre oferta e demanda, com ênfase para os modelos de equilíbrio geral e equilíbrio parcial. De modo geral esses modelos estão baseados na teoria de comércio internacional para estimar os desvios de mercado ocorridos por meio de mudanças políticas governamentais [16].

Os modelos de equilíbrio geral demandam certa quantidade de informações que por vezes não estão disponíveis, portanto, é preciso adotar hipóteses simplificadoras comprometendo os resultados obtidos. Em contraponto os modelos de equilíbrio parcial, embora minimizem a interferência do comportamento de um determinado mercado sobre o 
resto da economia, exigem uma menor quantidade de informações [1].

Os modelos de equilíbrio parcial costumam eleger um setor ou produto (apesar de poder ser expandido para multiprodutos) a ser analisado e examinam os efeitos de uma variação (exógena) do preço relativo sobre o equilíbrio do setor, supondo que a alocação no resto da economia permanece inalterada [16] e [17]. Portanto, no modelo de equilíbrio parcial, analisam-se os efeitos diretos de qualquer política de comércio sobre um determinado mercado. Por se tratar de uma commodity agrícola onde sua comercialização passa por origem e destino e sofre influência da elasticidade, os modelos de equilíbrio parcial ou espacial são os mais adequados para este trabalho.

Para este estudo é proposto um Problema de Complementariedade Mista (PCM) proposto por Rutherford (1995) [18] e Alvim (2003) [16] que consiste em um sistema de equações simultâneas (que podem ser lineares ou não lineares), que são descritas como desigualdades e que é alimentado pelas funções de oferta e demanda.

\subsection{APLICAÇÃO DO PCM PARA O CASO DO ETANOL}

Inicialmente foram definidos quais seriam as rotas de transporte de etanol analisadas, a partir de dados de oferta e demanda de etanol. Foram selecionadas as regiões de acordo com sua importação para a dinâmica comercial do produto, isso foi permitido através da análise do comportamento de algumas variáveis durante o ano de 2013: produção de etanol, rendimento médio, área cultivada, exportações, consumo e capacidade industrial das usinas sucroalcooleiras.

A Macrorregião 1 representa as mesorregiões de São José do Rio Preto e Ribeirão Preto, essa região representa cerca de $24 \%$ de todo etanol produzido no Brasil. As mesorregiões que compõem a Macrorregião 2 são: Araraquara, Piracicaba e Campinas, que juntas produzem aproximadamente $13 \%$ do total de etanol. A Macrorregião 3 é composta pelas seguintes mesorregiões: Araçatuba, Bauru, Presidente Prudente, Marília, Assis e Itapetininga, juntas são responsáveis por cerca de $14 \%$ da produção total de etanol no Brasil.

Os estados de Goiás e Mato Grosso do Sul juntos, produzem cerca de $22 \%$ do total brasileiro de etanol.

As regiões de excesso de demanda foram definidas a partir do seguinte critério: se a produção de etanol for maior que a quantidade consumida, então esta região é de excesso de oferta, e o inverso é caracterizado como uma região de excesso de demanda, portanto o estado de Minas Gerais embora seja o terceiro maior estado produtor, consome cerca de $90 \%$ de sua produção, não apresentando fluxo suficiente para ser região de excesso de oferta.

As regiões Nordeste, Sul e o estado do Rio de Janeiro, são responsáveis por absorver grande parte do excedente do etanol produzido na região Centro-Sul, e por isso são considerados como regiões de destino.

Em relação à demanda internacional, foram selecionados os países: Estados Unidos, Coreia do Sul e Países Baixos.

Foram realizadas também entrevistas a fim de identificar a percepção dos principais players do mercado. As entrevistas foram direcionadas para três tipos de grupos. No primeiro grupo estão às unidades produtoras de etanol localizadas nas regiões de interesse. O segundo grupo é composto por empresas transportadoras responsáveis pelo transporte e distribuição de etanol. No terceiro grupo estão as bases de distribuição e empresas responsáveis pela estocagem de etanol. A partir das entrevistas foi possível chegar ao valor de $15 \%$ utilizado como parâmetro no desconto da tarifa do frete ferroviário.

Os seguintes dados compõem o modelo: produção, consumo, preços de comercialização nacional e internacional, fretes dos diferentes modais, elasticidades-preço da oferta e demanda, que tiveram como base o ano de 2013.

Os dados de produção tiveram como fonte o Instituto Brasileiro de Geografia e 
Estatística (IBGE) [19]. Os dados de consumo e preço de comercialização nacional e internacional de combustíveis tiveram origem da base de dados da Associação Nacional do Petróleo, Gás Natural e Biocombustíveis [20]. Já os dados de elasticidade preço de oferta e demanda foram baseados em estudos desenvolvidos por Beiral (2011) [21], Boff (2009) [22], Luchansky e Monks (2009) [23]. Os custos de transportes tiveram como fonte o informe SIFRECA (2013) [24].

São propostos 2 cenários: o cenário 1 se trata de um cenário base onde são praticadas rotas rodoviárias e rodoferroviárias com os valores de tarifas praticadas atualmente. No cenário 2 foi proposto uma redução de $15 \%^{1}\left(\operatorname{tar}_{\mathrm{ik}}\right.$ e $\left.\operatorname{tar}_{\mathrm{ij}}\right)$ do frete do transporte ferroviário, alterando assim a dinâmica de transporte das rotas.

O PCM proposto para analisar o mercado de etanol brasileiro é apresentado a seguir:

Índices:

i :regiões de oferta de etanol $(i=1,2,3, \ldots . .5)$

$\mathrm{j}$ : regiões de consumo interno para o etanol $(\mathrm{j}=1,2,3$

$\mathrm{k}$ : regiões de demanda internacional para o etanol $(\mathrm{k}=1, . ., 3)$

r: rotas de transporte de etanol $(\mathrm{r}=1,2, . ., 18)$

Variáveis :

$\mathrm{p}_{\mathrm{i}}$ : preço de oferta

$\mathrm{p}_{\mathrm{j}}$ : preço do consumo interno

$\mathrm{p}_{\mathrm{k}}$ : preço da demanda internacional

$\mathrm{z}_{\mathrm{i}}$ : quantidade ofertada

$\mathrm{y}_{\mathrm{j}}$ : consumo interno

$\mathrm{y}_{\mathrm{k}}$ : consumo da demanda internacional

$\mathrm{x}_{\mathrm{ij}}$...: quantidade movimentada entre região de oferta e de consumo

Parâmetros:

t_...; custo de transporte

$\varphi_{\mathrm{i}}$ : preço-sombra da região de oferta i (de etanol)

$\lambda_{\mathrm{j}}$ : preço sombra da região de consumo $\mathrm{j}$

$\mu_{\mathrm{k}}$ : preço sombra da região de consumo $\mathrm{k}$

$$
\begin{aligned}
& 0 \leq \varphi_{i} \perp \sum_{j}^{I} x_{i j}+\sum_{k}^{K} x_{i k} \leq z_{i} \\
& 0 \leq \lambda_{j} \perp y_{j} \leq \sum_{i}^{I} x_{i j} \\
& 0 \leq \mu_{k} \perp y_{k} \leq \sum_{i}^{I} x_{i k} \\
& 0 \leq x_{i j} \perp p_{i}+t_{i j} \geq p_{j} \quad \forall_{i, j} \\
& 0 \leq x_{i k} \perp p_{i}+t_{i k} \geq p_{k} \quad \forall_{i, k}
\end{aligned}
$$

A equação (1) representa a restrição onde a quantidade comercializada tanto no mercado doméstico como no internacional não pode ser superior à quantidade produzida por essas regiões. A equação (2) ilustra a quantidade movimentada no mercado interno, enquanto a (3) representa o fluxo movimentado no mercado internacional.

\footnotetext{
${ }^{1}$ Essa redução de $15 \%$ no valor do frete ferroviário foi definida com base nas entrevistas realizadas durante a pesquisa
} 
O símbolo “ $\perp$ ” significa que pelo menos uma das desigualdades adjacentes deve ser satisfeita como igualdade estrita. As equações (4) e (5) estão descritas assim devido à uma formalidade da complementariedade para satisfazer as condições de Karush- Kuhn-Tucker.

As tarifas $\operatorname{tar}_{i k}$ e $\operatorname{tar}_{i j}$ foram incluídas devido à condição de lucro zero, apresentado na equação (5), onde há incorporação de novos parâmetros, a tar ${ }_{i k}$ e $\operatorname{tar}_{i j}$. Na presente proposta, estes parâmetros representam a variação do custo de transporte para os fluxos com destino ao mercado doméstico e internacional, logo:

$$
\begin{aligned}
& \left(p_{i}+t_{i k}\right) \cdot\left(1+\operatorname{tar}_{i k}\right) \geq p_{k} \forall_{i, k} \\
& \left(p_{i}+t_{i j}\right) \cdot\left(1+\operatorname{tar}_{i j}\right) \geq p_{j} \forall_{i, j}
\end{aligned}
$$

\section{RESULTADOS}

A Tabela 2 mostra os fluxos de comercialização do etanol com destino ao mercado doméstico por rota de transporte. As rotas R1, R3, R4, R5 e R6 apresentam um custo de transporte ótimo, sendo que R1, R3 e R5 são rotas de transporte rodoviário direto, enquanto R4 e R6 são rotas de transporte rodoferroviário. De acordo com o fluxo, a movimentação do cenário 1 com destino ao mercado doméstico ficou concentrada na utilização da intermodalidade, onde $46 \%$ das rotas são transportadas através do modal rodoviário, enquanto $54 \%$ utiliza a intermodalidade.

Tabela 2. Cenário 1: Fluxos de comercialização do etanol com destino ao mercado doméstico por rota de transporte em mil $\mathrm{m}^{3}$

\begin{tabular}{c|c|c|c|c|c|c}
\hline \multirow{2}{*}{ Origem** } & \multirow{2}{*}{ Destino } & \multicolumn{5}{|c}{ Rotas* } \\
\cline { 3 - 7 } & & $\mathrm{R} 1$ & $\mathrm{R} 3$ & $\mathrm{R} 4$ & $\mathrm{R} 5$ & $\mathrm{R} 6$ \\
\hline Macro 1 & Sul & & & 945,72 & & \\
\hline Macro 1 & Rio de Janeiro & & & & 53,20 & \\
\hline Macro 2 & Rio de Janeiro & & & & & 148,18 \\
\hline Macro 3 & Sul & & 810,00 & & & \\
\hline Goiás & Nordeste & 822,15 & & & & \\
\hline Goiás & Rio de Janeiro & & & & & 845,18 \\
\hline & Total & 822,15 & 810,00 & 945,72 & 53,20 & 993,36 \\
\hline
\end{tabular}

*Rotas ímpares (R1, R3 e R5) são rotas rodoviárias, enquanto as rotas pares (R4 e R6) são rotas intermodais.

**Macro1:São José do Rio Preto e Ribeirão Preto

Macro2: Araraquara, Piracicaba e Campinas

Macro3: Presidente Prudente, Marília, Assis, Itapetininga, Araçatuba, Bauru

Fonte: Dados da pesquisa (2015).

A seguir a Tabela 3 apresenta as rotas com destino ao mercado internacional. 
Tabela 3. Cenário 1: Fluxos de comercialização do etanol com destino ao mercado internacional por rota de transporte em mil $\mathrm{m}^{3}$

\begin{tabular}{c|c|c|c|c|c}
\hline \multirow{2}{*}{ Origem** } & \multirow{2}{*}{ Destino } & \multicolumn{4}{|c}{ Rotas* } \\
\cline { 5 - 6 } & & \multirow{2}{*}{$\mathrm{R} 8$} & $\mathrm{R} 9$ & $\mathrm{R} 11$ & \multirow{2}{*}{$\mathrm{R} 13$} \\
\hline Macro 1 & Estados Unidos & 406,90 & & & \\
\hline Macro 2 & Holanda & & 169,11 & & \\
\hline Macro 2 & Coreia do Sul & & & 371,45 & \\
\hline Macro 2 & Resto do & & & & \multirow{2}{*}{ Mundo } \\
\cline { 5 - 6 } & Estados Unidos & $1.697,66$ & & & \\
\hline Mato Grosso do Sul & Total & $2.104,56$ & 169,11 & 371,45 & 53,99 \\
\hline
\end{tabular}

*Rotas ímpares (R9, R11 e R13) são rotas rodoviárias, enquanto a rota par (R8) é rota intermodal

**Macro1:São José do Rio Preto e Ribeirão Preto

Macro2: Araraquara, Piracicaba e Campinas

Macro3: Presidente Prudente, Marília, Assis, Itapetininga, Araçatuba, Bauru

Fonte: Dados da pesquisa (2015)

Nota-se que para o transporte com destino ao mercado internacional, a rodovia SP 348 é um importante corredor de acesso ao porto de Santos. A Rodovia dos Bandeirantes em 2013 foi considerada a rodovia em melhores condições de conservação pela pesquisa rodoviária da Confederação Nacional do Transporte e junto com a Rodovia Anchieta e com o Rodoanel Mario Covas compreende no maior corredor rodoviário de exportação do Brasil. Possivelmente a boa condição desta via torna seu custo menor e mais competitivo do que utilizando a ferrovia.

Em relação aos volumes movimentados com destino ao mercado internacional do cenário 1, observa-se que apenas $22 \%$ utiliza o modal rodoviário direto, enquanto $78 \%$ é mais competitivo utilizando a intermodalidade.

Neste cenário a maioria das rotas é transportada utilizando a intermodalidade (64\%), enquanto o modal rodoviário direto é responsável por $46 \%$ do volume movimentado no cenário 1.

Em seguida será apresentado o cenário 2 onde foi adicionado as tarifas $\operatorname{tar}_{\mathrm{ik}} \mathrm{e} \operatorname{tar}_{\mathrm{ij}}$ que representam um desconto da ordem de $15 \%$ no valor dos fretes ferroviários buscando analisar o quanto um desconto influencia na adoção da intermodalidade. A Tabela 4 apresenta os fluxos de comercialização do etanol com destino ao mercado doméstico por rota de transporte.

Tabela 4. Cenário 2: Fluxos de comercialização do etanol com destino ao mercado doméstico por rota de transporte em mil $\mathrm{m}^{3}$

\begin{tabular}{c|c|c|c|c}
\hline \multirow{2}{*}{ Origem** } & \multirow{2}{*}{ Destino } & \multicolumn{3}{|c}{ Rotas* } \\
\cline { 3 - 5 } & & $\mathrm{R} 1$ & $\mathrm{R} 4$ & $\mathrm{R} 6$ \\
\hline Macro 1 & Sul & & 781,14 & \\
\hline Macro 2 & Sul & & 166,05 & \\
\hline Macro 2 & Rio de Janeiro & & & 199,95 \\
\hline Macro 3 & Sul & & 809,94 & \\
\hline Goiás & Nordeste & 819,83 & & \\
\hline Goiás & Rio de Janeiro & & & 849,03 \\
\hline & Total & 819,83 & $1.757,13$ & $1.048,98$ \\
\hline
\end{tabular}


*Rota ímpar (R1) é rota rodoviária, enquanto as rotas pares (R4 e R6) são rotas intermodais.

**Macro1:São José do Rio Preto e Ribeirão Preto

Macro2: Araraquara, Piracicaba e Campinas

Macro3: Presidente Prudente, Marília, Assis, Itapetininga, Araçatuba, Bauru

Fonte: Dados da pesquisa (2015)

Em relação aos volumes com destino ao mercado doméstico, no cenário 2, cerca de $23 \%$ são transportados via modal rodoviário direto, enquanto $77 \%$ são mais competitivos utilizando a intermodalidade.

Nota-se que no cenário 2 em relação às rotas do mercado doméstico, para os fluxos com destino à região Nordeste o transporte ótimo ainda é o rodoviário (100\%) e possui como origem o estado de Goiás, porém, para as rotas com destino à região Sul e ao estado do Rio de Janeiro, o resultado ótimo apresenta uma maior utilização das rodas intermodais.

$\mathrm{Na}$ Tabela 5 a seguir serão apresentados os resultados do cenário 2 para o mercado internacional.

Tabela 5. Cenário 2: Fluxos de comercialização do etanol com destino ao mercado internacional por rota de transporte em mil $\mathrm{m}^{3}$

\begin{tabular}{c|c|c|c|c|c}
\hline \multirow{2}{*}{ Origem** } & \multirow{2}{*}{ Destino } & \multicolumn{4}{|c}{ Rotas* } \\
\cline { 3 - 6 } & & $\mathrm{R} 8$ & $\mathrm{R} 10$ & $\mathrm{R} 12$ & $\mathrm{R} 14$ \\
\hline Macro 1 & Estados Unidos & 402,07 & & & \\
\hline Macro 1 & Holanda & & 168,80 & & \\
\hline Macro 1 & $\begin{array}{c}\text { Resto do } \\
\text { Mundo }\end{array}$ & & & & 55,97 \\
\hline Macro 2 & Coreia & & & 377,25 & \\
\hline Mato Grosso do Sul & Estados Unidos & $1.702,16$ & & & \\
\hline & Total & $2.104,23$ & 168,80 & 377,25 & 55,97 \\
\hline
\end{tabular}

* Rotas ímpares são rotas rodoviárias, enquanto as rotas pares (R8, R10, R12 e R14) são rotas intermodais.

**Macro1:São José do Rio Preto e Ribeirão Preto

Macro2: Araraquara, Piracicaba e Campinas

Macro3: Presidente Prudente, Marília, Assis, Itapetininga, Araçatuba, Bauru

Fonte: Dados da pesquisa (2015)

Em relação às rotas com destino ao mercado internacional, para todas as rotas ótimas que o modelo encontrou a opção de transporte é a intermodalidade. São rotas competitivas então, R8, R10, R12 e R14. Se compararmos com o cenário 1 é possível observar uma disparidade em relação a distribuição dos modais, já que no cenário 2 a movimentação com destino ao mercado externo ficou concentrada $100 \%$ na intermodalidade.

Neste cenário apenas $13 \%$ das rotas são transportadas via rodoviário direto, diferente do anterior, onde $36 \%$ utilizavam a rodovia como principal meio de transporte. de comercialização do etanol com destino ao mercado doméstico por rota de transporte.

Para o cenário 1 , os resultados indicam uma maior utilização da intermodalidade (64\%) em relação à utilização do transporte via rodoviário direto (36\%) para as movimentações de etanol, porém, vale ressaltar que este é o cenário base, onde os valores das tarifas utilizados são os praticados atualmente, sem descontos.

Quando se aplica uma redução de $15 \%$ nos valores dos fretes ferroviários (cenário 2), a intermodalidade passa a ser mais competitiva do que a utilização do modal rodoviário direto. O cenário 2 aponta que com a inserção das $\operatorname{tar}_{i k}$ e $\operatorname{tar}_{i j}$ apenas $13 \%$ das rotas de transporte de etanol são movimentadas via modal rodoviário e $87 \%$ das rotas apontam a intermodalidade como opção mais eficiente. Vale ressaltar que no cenário 2 há uma grande alteração de meio de transporte nas rotas com destino às exportações. No cenário 1 cerca de 78\% das rotas com destino ao mercado internacional eram transportadas utilizando a 
intermodalidade, porém, quando se aplica o desconto de $15 \%$ no valor do frete ferroviário, $100 \%$ das rotas com destino à exportação passam a aderir à intermodalidade, e o transporte para o Porto de Santos através do modal rodoviário direto se mostra menos competitivo.

A grande diferença observada nos dois cenários entre a adoção de intermodalidade ou da utilização somente do modal rodoviário pode ser vista no transporte com destino ao Porto de Santos, onde já no cenário $2100 \%$ das rotas indicam que a intermodalidade se mostra mais competitivo para esse destino.

Em relação ao mercado interno, quando se compara os dois cenários, foram identificadas de que $35 \%$ das rotas são mais competitivas no modal rodoviário direto, enquanto que, $65 \%$ são mais competitivas utilizando a intermodalidade. Isso indica que novos investimentos em infraestrutura intermodal são necessários para aumentar o uso da intermodalidade nas rotas de consumo doméstico e manter o nível de competitividade.

\section{CONSIDERAÇÕES FINAIS}

Os avanços conquistados pelo agronegócio nos últimos anos estão sendo acompanhados por diversos setores da economia, porém a configuração logística atual tem revelado diversas fragilidades em relação ao transporte e armazenagem de cargas agrícolas.

A demanda mundial por etanol está aumentando em razão de uma maior busca por fontes de combustíveis renováveis, sendo assim, a logística deve procurar se adequar de forma que seja possível obter vantagens competitivas que reflitam no preço total do produto.

Essa pesquisa buscou analisar as alternativas de transporte para diferentes rotas de etanol frente às condições da logística vigentes no Brasil, avaliando as implicações das limitações da infraestrutura de transporte na promoção do aumento da competitividade do etanol no mercado nacional e internacional. Além disso, buscou-se avaliar as alternativas de transporte de etanol com a intenção de apontar qual a forma mais eficiente de realizar o transporte para determinadas rotas. Foi feito um levantamento de dados do mercado de etanol para se entender a dinâmica de comercialização deste produto. Também foi realizada uma revisão sobre os métodos de transporte para assim apresentar as características e especificidades dos modais de transporte terrestres.

O transporte das cargas agrícolas é uma atividade extremamente onerosa devido ao fato de que os produtos apresentam baixo valor agregado, sendo assim, o custo de transportar tem uma grande participação no custo total do produto, afetando sua competitividade.

O Brasil enfrenta atualmente o risco de um apagão logístico, como já mencionado anteriormente, além dos desafios em relação à capacidade de armazenamento e transporte, que acabam afetando a competitividade do produto. No caso do etanol, embora o Brasil ocupe a posição de segundo maior produtor mundial, as deficiências do sistema logístico fazem com que o produto perca competitividade em relação aos grandes players mundiais.

Além do risco do apagão logístico, o setor sucroalcooleiro, sobretudo o segmento etanol tem passado por uma crise nos últimos anos. A queda na produção da safra 2014/2015 já é um reflexo das instabilidades pelas quais o setor está passando, logo, se vê necessário o desenvolvimento de políticas públicas para que segmento consiga se recuperar nas próximas safras.

Uma agenda de investimentos é necessária, não somente em infraestrutura de transporte, mas sim em toda cadeia logística, dada a importância e o peso do fator logístico no preço total das cargas agrícolas.

Novas políticas públicas que estimulem a utilização da intermodalidade como meio de obter ganhos competitivos devem ser adotadas, de forma a dar acesso aos principais players do setor agrícola à utilização da intermodalidade.

A hipótese da pesquisa de que a intermodalidade é mais competitiva se confirma já que com a redução dos custos de transporte do modal ferroviário e a implementação de um 
novo sistema dutoviário aumentam-se os fluxos de movimentação.

Uma das limitações do modelo é o fato de não se considerar o subsídio do etanol dos Estados Unidos, como a proposta visa analisar, sobretudo, os fluxos do mercado doméstico, não foi incluído no modelo o subsídio norte-americano. Vale ressaltar que o etanol brasileiro poderia ser mais competitivo se não existisse o subsídio norte-americano, portanto análises futuras podem indicar o efeito do subsídio sobre o etanol brasileiro.

Para as pesquisas futuras pode-se implementar de um modelo de equilíbrio espacial que tenha como abrangência apenas o mercado interno, mas que considere um segundo produto, a gasolina, que atualmente é o principal concorrente do etanol dentre os combustíveis, neste caso o modelo será multi-produto.

\section{REFERÊNCIAS BIBLIOGRÁFICAS}

[1] OLIVEIRA, C. A. de. Infraestrutura de transportes: análise dos principais modais no estado de São Paulo. Revista Formação Online, Presidente Prudente, v. 1, n. 19, p.124150, jan. 2011.

[2] BELIK, W.; RAMOS, P.; VIAN, C.E.F. Mudanças institucionais e seus impactos nas estratégias dos capitais do complexo agroindustrial canavieiro no Centro Sul do Brasil (compact disc). In: Congresso Brasileiro de Economia e Sociologia Rural. 36 p., Poços de Caldas, 1998. Anais... Brasília: SOBER, 1998.

[3] SOUZA FILHO, H. Geração e distribuição de excedente em cadeias agroindustriais: implicações para a política agrícola. In: : Antônio M. Buainain; Eliseu Alves; José M. S.; Zander Navarro,. (Org.) "O mundo rural no Brasil do século 21". Brasília, EMBRAPA. Parte 2, cap. 5, p. 319-336, 2014.

[4] CARVALHO, L.B.; CAIXETA FILHO, J.V. Comportamento do mercado de preços de fretes rodoviários de açúcar para exportação no estado de São Paulo. In: Revista de Economia e Agronegócio. Vol.5 nº 1, Jan-Mar, 2007.

[5] LEMOS, P.; MESQUITA, F.; DAL-POZ, M. E.; SOUZA, L. G. A . Panorama e Desempenho Recente do Setor Sucroenergético: Condições para um Novo Ciclo? In: SALLES FILHO, Sergio (Org.). Futuros do Bioetanol: O Brasil na Liderança. Rio de Janeiro: Elsevier, 2015. p. 9-33.

[6] FLEURY, P.F. A infra-estrutura e os desafios logísticos das exportações brasileiras. 2005. Disponível em: <http://www.cel.coppead.ufrj.br/fs-public.htm>. Acesso em: 01/Nov/2013.

[7] BOWERSOX, D. J.; CLOSS, D. J.; COOPER, M. B. Gestão logística de cadeias de suprimentos. 5. ed. Porto Alegre: Bookman, 2006.

[8] UNIÃO DA INDÚSTRIA DE CANA-DE-AÇÚCAR (UNICA). Histórico de produção e moagem. Disponível em: <http://www.unicadata.com.br/historico-deproducao-e-moagem.php?idMn=31\&tipoHistorico=2> . Acesso em 3 jan de 2015.

[9] RENEWABLE FUElS ASSOCIATION (RFA). Monthly U.S. Fuel Ethanol Production/Demand. Disponível em: <http://ethanolrfa.org/pages/monthly-fuelethanol-production-demand>.

[10] MAPA- MINISTÉRIO DA AGRICULTURA, PECUÁRIA E ABASTECIMENTO. Projeções do Agronegócio: Brasil 2009-2010 a 2019-2020. Brasília: Mapa/ACS, 2010. Disponível em <http://goo.gl/M6YDyq>. Acesso em 30 de dez. 2014. 
[11] BRASIL. Ministério do Desenvolvimento, Indústria e Comércio Exterior. Secretaria de Comércio Exterior. Exportação NCM Brasileira. Disponível em: < http://aliceweb.mdic.gov.br/> Acesso em: 14 mai 2014.

[12] OLIVEIRA, A. L. R. de. Logística de Etanol no Brasil. In: SALLES FILHO, Sergio (Org.). "Futuros do Bioetanol: O Brasil na Liderança". Rio de Janeiro: Elsevier, 2015. p. 9-33.

[13]__ Perfil da logística de transporte de soja no Brasil. Informações Econômicas, São Paulo, v. 36, n.1, p. 17-25, 2006.

[14] FLEURY, P. F. Gestão estratégica do transporte, 2002. Disponível em: <http://www.cel.coppead.ufrj.br/fspublic.htm>. Acesso em: 14 jul de 2014.

[15] LÍCIO, A. Os eixos estruturadores e dos corredores de transportes. Revista de Política Agrícola, Brasília, v.9, n.4, p.3-4, 1995.

[16] ALVIM, A. M. Os impactos dos novos acordos de livre comércio sobre o mercado de arroz no Brasil: um modelo de alocação espacial e temporal. 2003, 221 p. Tese (Doutorado em Economia) -Universidade Federal do Rio Grande do Sul, Porto Alegre

[17] CAVALCANTE, J.; MERCENIER, J. Uma avaliação dos ganhos dinâmicos do Mercosul usando equilíbrio geral. Pesquisa e Planejamento Econômico, Rio de Janeiro, v.29, n.2, 1999.

[18] RUTHEFORD, T.F. Extension of GAMS for complementarity problems arising in applied economic analysis. Journal of Economics Dynamics \& Control, v. 19, 1995, p. 1299-1324.

[19] IBGE. Instituto Brasileiro de Geografia e Estatística. Definições. Disponível em: <http://www.ibge.gov.br>. Acesso em: 5 de Jun. de 2010.

[20] ANP - AGÊNCIA NACIONAL DO PETRÓLEO, GÁS NATURAL E BIOCOMBUSTÍVEIS. Anuário Estatístico 2012. Disponível em: <http://www.anp.gov.br/>. Acesso em jun. 2014.

[21] BEIRAL, P. R. S. O mercado brasileiro de etanol: concentração e poder de mercado sob a ótica da nova organização industrial empírica. São Paulo, 2011. 108f. Dissertação (Mestrado em Economia Aplicada) - Escola Superior de Agricultura Luiz de Queiroz, Universidade de São Paulo, Piracicaba, 2011.

[22] BOFF, H. P., 2009, "O mercado interno do etanol: Modelo e Estimação do Preço de Equilibrio", Seminários de pesquisa, 17032, IE/UFRJ, Rio de Janeiro, 17 Março.

[23] LUCHANSKY, M. S. e MONKS, J. Supply and Demand Elasticities for the United States Ethanol Market. Energy Economics, v. 31, n. 3, p. 403-410, 2009.

[24] INFORME SIFRECA. Sistema de informações de fretes para cargas agrícolas. Piracicaba: [s.n.], 2013.

[25] UNICA - UNIÃO DA INDÚSTRIA DE CANA-DE-AÇÚCAR. Exportação anual de etanol por local de embarque (mil litros). Disponível em: <.http://www.unicadata.com.br/listagem.php?idMn=24>. Acesso em jan 2015. 